Article

\title{
Physical Modelling of Bridge Pier Scour and its Effect on Dynamic Response: Towards Real-Time Monitoring of Bridges
}

\author{
Fatemeh Rahimi *, Alireza Keshavarzy and Mohsen Askari \\ Centre for Infrastructure Engineering (CIE), Western Sydney University, Kingswood 2747 New South Wales, \\ Australia \\ *Correspondence:19843269@student.westernsydney.edu.au;fatemehrahimi998@gmail.com
}

\begin{abstract}
The generation of vortices around bridge piers can lead to removal of riverbed materials from around piers, especially during flood events and heavy rainfalls, which can compromise the stability of the bridge and consequently its failure, if not properly detected and mitigated. Bridge failures pose serious threats to the local socio-economic and public safety and can cost lives. As such, real-time monitoring and early w arning systems for scour-induced bridge failure can serve as a vital tool to protect the community and civil infrastructure against disastrous events. Vibrationbase monitoring of bridge scour is an attractive option due to its low cost and relatively easy installation without the need to block the road and close the bridge to traffic. While limited number of previous studies have show $n$ the capabilities of acceleration-based monitoring techniques in this area of research, they generally lack a rigorous framew ork for data analysis within and relating those to evaluate scour. This paper is an attempt to provide such framew ork that would enable a fast and low -cost analysis of vibration data within a physical modelling study on a simplified bridge pier. To achieve this, three experiments were conducted on an ideal single-pier scaled model bridge in a hydraulic flume, where w ater flows at a velocity near the criticalvelocity for the sand bed which in turn generates a scour hole around the pier. Then, the vibration data recorded using two mounted wireless accelerometers, were used to conduct an operational modal analysis through which the natural frequencies are extracted. The extracted natural frequencies and measured scour depths are then used to provide a chart that relates these tw o parameters. The results of this study show ed the promising capability of the vibration-based data analysis in finding this relationship, indicating an up to around $30-50 \%$ reduction in natural frequencies as a result of around $50 \%$ scour ratio (ratio of maximum scour depth to buried depth), and beyond 50\% scour ratio the natural frequencies remain constant. While the data presented in this paper are preliminary, they clearly show a promising potential for application in real-time monitoring of bridge stability under the effect of local scour and further works are underway to enrich the experimental data and empower the proposed methodologies at the laboratory scale.
\end{abstract}

Keywords: bridge stability; scour; physical modelling; structuralhealth monitoring; modal analysis

\section{Introduction}

Bridges have a considerably large service life which sometimes reaches or surpasses 100 years, and their resilience against different and rare environmental conditions need to be carefully evaluated. Depending on the size and application of a bridge, its failure can pose a substantial threat to public safety and local infrastructures and civil services. Lagasse, Zevenbergen [1] estimated that in the United States, repairing damages induced by flood alone costs around \$50 million per annum, and that overlooks the consequences of catastrophic bridgefailures. In addition, it is estimated that the indirect costs caused by bridge restorations (e.g. long detour and lost production time) is about five times larger than the cost of bridge repair[2]. Cook, Barr [3] has conducted one of the most 
comprehensive studies on bridge failure rates and found that the leading cause of bridge failure is scour, accounting for $60 \%$ of them. Scour is defined as the removal of the material from bed and banks of rivers as a result of erosive action of flowing water [4,5]. Scours can be classified into three main categories of "natural scour", "contraction scour" and "local scour" as depicted in Figure 1a [6]. Natural scour is the natural erosion of the streambed without obstacle due to natural variability of river stream flows and sedimentation regimes, and it takes place on a large scale on the riverbed [7]. Contraction scour occurs due to flow contraction when flow velocity increase as a result of reduced flow cross section (due to bridge abutments, for instance) and it usually takes place within the whole width of river stream. Local scour occurs due to a local concentration of turbulence generated by presence of objects (e.g., bridge piers and abutments) that obstruct the flow of $\mathrm{w}$ ater [8]. Local scour has a smallest influence zone compared to the other tw o scour types, but it occurs in the close vicinity of the structures and hence it is the most critical. Local scour is mainly caused by horseshoe vortices which is formed due to the downw ard hydraulic gradient in front of pier as a result of lower dynamic pressure near the bed surface [9]. This results in a downw ard flow tow ards the bed and the separated boundary layer rolls up to form a swirling vortex around the pier which then tr ails off downstream [10]. On the downstream behind the pier, the rotation in the boundary layer over the surface of the pile where shear layers originated from the sides of the pier roll up to form wake vortices [10]. The schematic of these vortices generated around the pier is illustrated in Figure 1b. The combined effect of the horseshoe and wake vortices leads to liquefaction of which allow s the riverbed soil to be carried off with current and be deposited downstream which in turn creates a scour hole in front of the pier and a deposit mound behind the pier (Figure 1c). Development of scour hole will then reduce the stiffness of thebridge foundation which can lead to failure of piers [11].

(a)

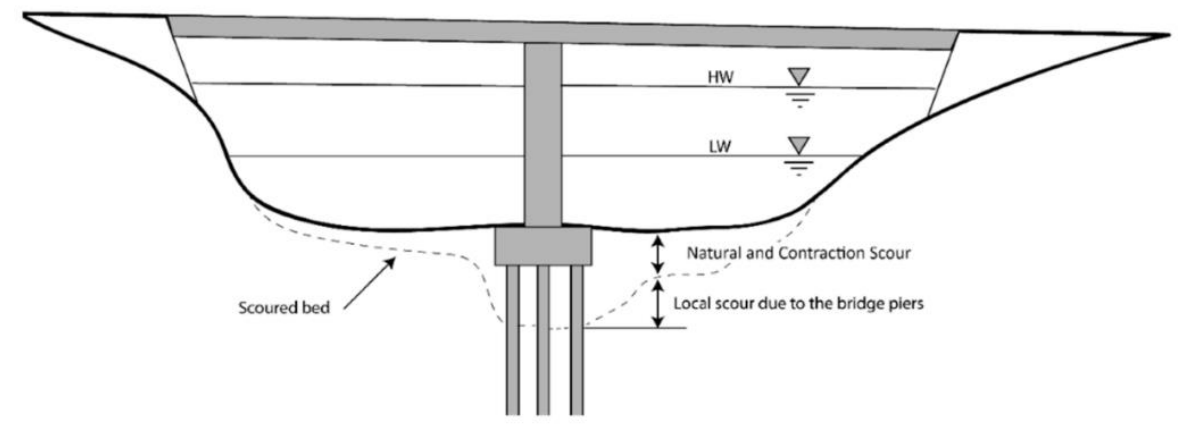

(b)

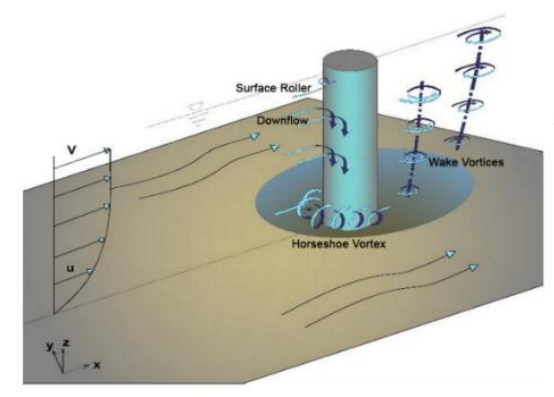

(c)

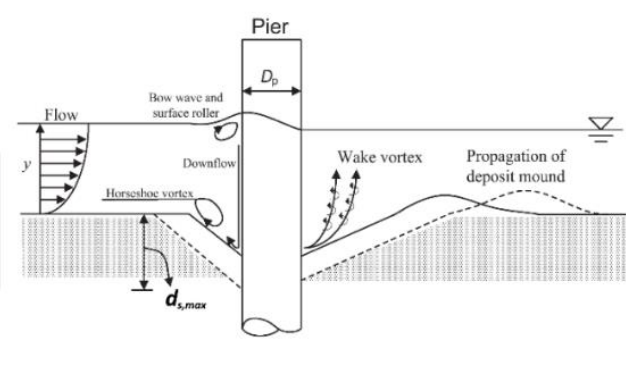

Figure 1. a) de finition and general and local scours [8], b) schematic of local scour a round cylindrical pier [12], and c) illustration of scour pattern around the pier with maximum scour depth definition, $\boldsymbol{d}_{\text {s, } \max }[$ after 13].

The formation and characteristics of the horseshoe and w ake vortices in the vicinity of the bridge pier has been the subject of extensive experimental research over the last three decades [e.g. 14, 1521]. Despite the aforementioned studies along with other investigations, precise prediction of scour occurrence and its characteristics and its effect on structural stability of bridges is still difficult [11], mainly due to the spatial and temporal uncertainties associated with characteristics of water flow, 
bed materials and structural mechanics and hence most of studies have employed empirical relationships or machine learning [22-27].

The above-mentioned shortcomings with predictive approaches, therefore, highlight the importance of monitoring of bridges to assess their susceptibility to scour and scour-induced instability, which in turn can mitigate the potentially disastrous consequences of bridge failure such as the notable catastrophic events reviewed by Jones and Richardson [28]. Several studies have review ed monitoring techniques for assessment of scour in bridge piers and abutment s [e.g. 7, 11,29] and have compared their relative advantages and disadvantages and have found that vibration -based monitoring techniques showed promising potential as a cost-effective and precise solution to bridge scour monitoring. This is because sensors used in vibration-bases monitoring techniques are easy to install, non-intrusive, very accurate and durable and relatively cheap compared to other types of sensors such as Ultrasonic, TDR (Time Domain Reflectometry), capacitor, and wireless acoustic sensors [11]. How ever, as Wang, Yu [29] pointed out, the vibration-based modal analysis for bridge scour is still under development and needs further research. The shortcomings with the existing studies in this area is discussed below and then we explain how our innovative approach can overcome these issues.

The vibration-based monitoring of structures is a topic of interest in many civil engineering applications and has recently gained a lot of attention for bridge scour detection. The overall response of a bridge is mainly governed by the soil-w ater-structure interactions [30] and understanding these interactions can be very complex as many parameters are involved. While predicting the dynamic response of bridges can be quite difficult, measuring the changes in the dynamic characteristics is relatively straightforward. Accelerometers can be placed on bridge pier and their data can be used to detect fluctuations in dynamic characteristics of the bridge [31]. It has been shown that presence of scour hole can significantly change the dynamic response of a bridge pier and more specifically the natural frequency [e.g. 32]. Yao, Darby [32] conducted laboratory scale experiments in a flume, where they showed that the first three predominant natural frequencies of pier (PNF) reduced with increasing scour depth. Briaud, Yao [33] improved upon the previous study by studying the effect of shallow and deep foundation and detected a similar decreasing trend of PNF. Tserng, Ju [34] developed a physical model of 3-pier bridge under extreme flood condition and installed wireless accelerometer to record the vibration response of piers and calculated the natural frequency of each pier. Prendergast, Hester [31] and Bao, Liu [35] neglected the complex fluid-structure and fluid-soil interactions, and conducted experiments on a monopile without the effect of flowing water where the scour was artificially induced by removing soil from around the pile. They also found a decreasing trend for natural frequency as more materials removed from around the pile. These studies, however, only used a Fast Fourier Transform (FFT) on acceleration data induced by an impact hammer and then estimated the natural frequency from the local maxima in FFT plots. Such method of data analysis cannot beeasily used for real world bridge environment with a broad range of ambient vibrations. Lin and Chang [36] used velocity sensors to record the dynamic response of piers in a hydraulic flume and to monitor the rigid body motion cause by scouring. How ever, they introduced an instability index as a diagnostic indicator to evaluate the susceptibility of the bridge to failure instead of a transient evaluation of natural frequency versus scour depth. Mao, Mazzotti [37] conducted field experiments on a bridge using impact hammer and employed an experimental modal analysis to calculate the modal parameters with the known input and output using the Frequency Response Function (FRF). The known input-output algorithms for estimation of natural frequency, require conducting impact tests on the bridge pier and hence cannot be used as a continuous realtime monitoring strategy.

This paper aims to address the above-mentioned shortcomings with the studies listed previously to get a step closer to real-time monitoring of bridge pier scour. In order to achieve that, a physical model was developed where a hydraulic flume filled with sand as the riverbed to ensure the complex fluid-structure and fluid-soil interactions are properly considered (as opposed to studies without flowing water). A scaled single-pier model bridge was buried into soil and a controlled water flow established in the flume to allow steady-state flow-induced scour around pier. Accelerometers were 
used to collect the acceleration data of the pier which were then analysed within a novel framew ork which allows fast Operational Modal Analyses (OMA) with unknown input excitation and using acceleration data of output response through Frequency Domain Decomposition (FDD). FDD [38,39] had a growing interests in structural health monitoring [e.g. 40,41, 42]. How ever, its application in bridge scour identification is limited [e.g. 43] and FFT-based identification of PFN is widely used [e.g. $11,44,45]$, despite its prospects for real-time modal identification.

This paper provides new experimental dataset that gives invaluable insights on the evolution of scour hole under clear-water conditions, while the framework used for data analysis allows the estimation of PNF which can then be related to the measured scour depth. Following the report of the results and their discussion, this paper discusses the advantages and limitat ions of this study and will provide future research directions for its application in real-time monitoring of scour detection in existing bridges which can lead to early-w arning systems for catastrophic failure. In this paper an automatic EFDD method is developed which is capable of extracting the modal parameters of the pier using an output signal only; that is we do not need to have any information about the input excitation and it can even be a white noise. As opposed to the methods used in previous studies which does not provide a precise estimation of PNFs especially for short time intervals, our framew ork allows conducting an operational modal analysis at much shorter time intervals (5 minutes in this study) with lower number of acceleration data points, and as such this paper is the first to provide the PNFs of piers affected by scours at such small time intervals. In addition, a technique for identification and removal of harmonic components has been employed in data processing which enhances the accuracy and the resolution of the measurements; to the authors' knowledge this has not been used in any studies on vibration-based monitoring of piers. Therefore, the framew orkintroduced in this paper is a novel approach that helps us improve and speed up the identification of changes in natural frequency vs time and/or scour depth.

\section{Materials and Methods}

In order to simulate the condition of scour development under the river flow regime, a series of flume experiments were conducted at the Western Sydney University's Hydraulic Laboratory. The experimental setup and procedures along with the data analysis methodology is explained in this section.

\subsection{Experimental Setup and Procedure}

Experiments were conducted in a rectangular hydraulic flume with dimensions of $5000 \times 500 \times 300 \mathrm{~mm}$ (Length $\times$ Depth $\times$ Width). The walls are made of Plexiglass sheets with $10 \mathrm{~mm}$ thickness. The materials selected to mimic the riverbed materials is a uniform sand with mean particle diameter $\left(d_{50}\right)$ of $0.78 \mathrm{~mm}$. The water is supplied with a circulating pump system and the flume is equipped with a flap gate valve at the downstream that regulates water discharge to set the water level to a desired depth. A pier made of a PVC pipe with an outer diameter of $25 \mathrm{~mm}$ buried into the sand to a depth of $d_{b}$ and its top end was attached to a straight board to simulate the bridge deck. The pier diameter w as chosen to follow Melville and Coleman [5] where they recommended that the ratio of pier diameter $(D)$ to the width of flume $(W)$ needs to be greater than 0.1 in order to minimise the effect of contraction on scour depth. The schematic of the experimental setup and dimensions of the physical models are depicted in Figure 2.

To avoid the effect of water depth on local scour depth, the ratio of pier diameter to water depth ratio should be less than 0.7 according to Melville and Coleman [5]. As such, the depth of water in this study was chosen to be $100 \mathrm{~mm}$. In order to prevent livebed scour condition (wherebed particles are transported by the flowing w ater and hence filling the scour hole), the w ater flow rate was chosen to be smaller than a critical velocity which mainly depends on water depth and particle size [46]. This critical velocity for the experimental setup in this critical velocity was estimated to be $0.333 \mathrm{~m} / \mathrm{s}$ after Melville and Coleman [5] and hence a mean water velocity of $0.33 \mathrm{~m} / \mathrm{s}$ (equivalent to a volumetric flow rate 9.9 litre/s) was chosen in this study. The mean water velocity is chosen close to critical 
velocity to facilitates the local scour development under clear water condition and hence replicates the condition under high river flow conditions such as those following extended heavy rainfalls.

The first step of the test was to install the pier at the centre of the flume. After that, the bed materials w ere placed and levelled, hence the pier can be considered as a free-standing (floating) pile. Then the flume was slowly filled with water from downstream, ensuring the sand bed was not disturbed. Once the depth of water reached the target depth of $100 \mathrm{~mm}$, the upstream flow rate was gradually increased to the design rate of 9.9 litre/s while flap gate valve was adjusted to maintain the water depth of $100 \mathrm{~mm}$. The experiments were run until the maximum scour depth reached to 90$95 \%$ of the pier's burial depth $\left(d_{b}\right)$.

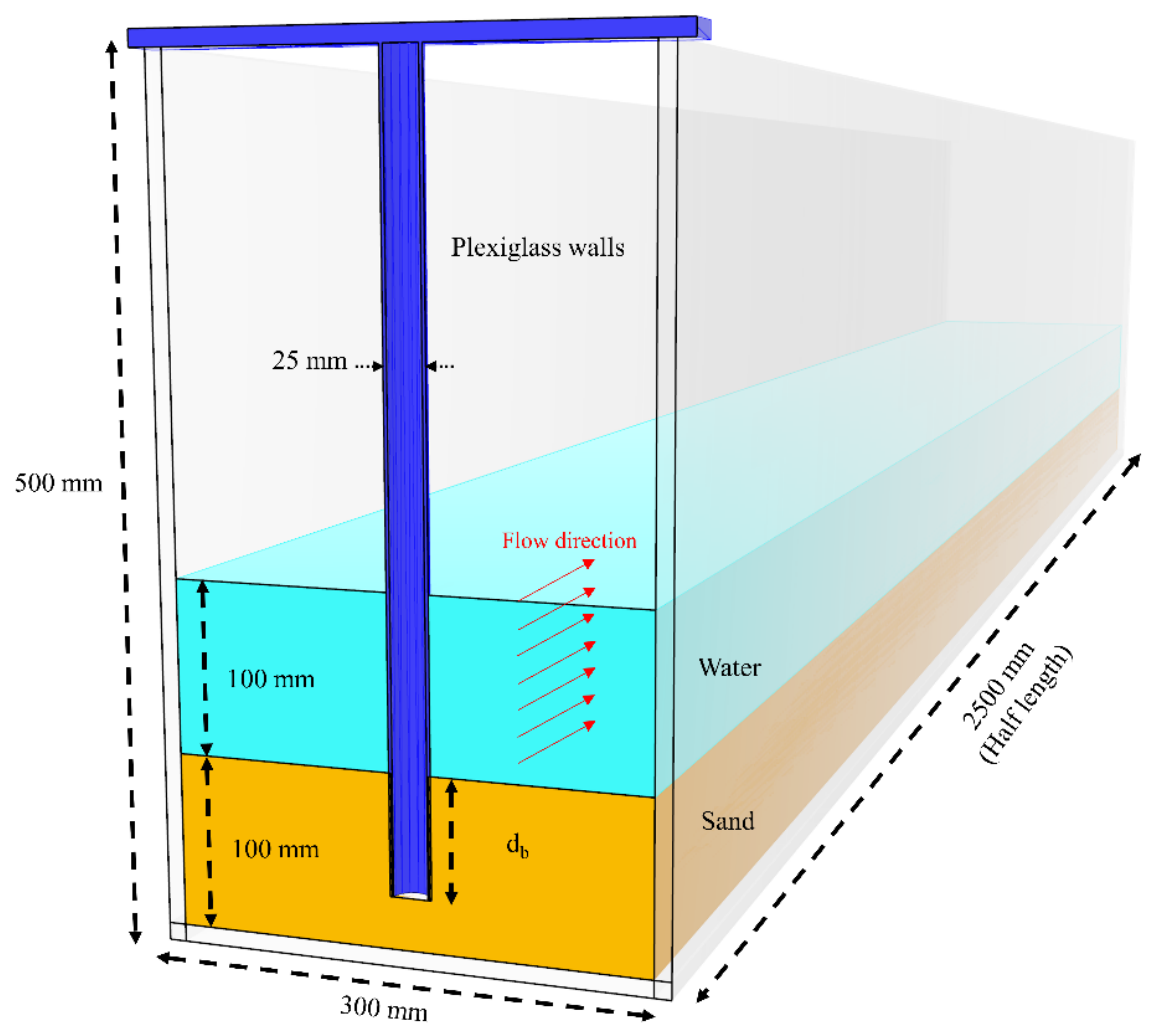

Figure 2. schematic of the hydraulic flume and model pier used in the experiments (section view at the half length).

In order to measure the maximum scour depth, a laser range finder was mounted on the front side of the pier (upstream) whose data are recorded every few minutes. Care was taken to ensure that the rangefinder emits light perpendicular to the w ater surface to minimise the backscattered light off the water surface. The rangefinder provides an accurate estimation of the distance from the sensor to the surface of the sand bed $( \pm 0.2 \mathrm{~mm})$ and its changes represent the instantaneous maximum depth of scour hole. Two wireless accelerometers were also mounted on the back side of the pier (downstream) which record the accelerations in the flow direction at a frequency of $124 \mathrm{~Hz}$. One of these accelerometers is located at the top of the pier near the bridge deck and the other one is mounted level $7 \mathrm{~cm}$ of the pier surface.

The accelerometers store data on their dedicated memory on specified time intervals which will be used for FDD analysis upon completion of the test. Figure 3 show s photographs of the hydraulic flume, its pump, and instruments mounted on the pier during testing. It should be noted that throughout the test, some vibration was forced to the deck to simulate the effect of ambient vibrations such as those in real bridge environment (e.g. due to passing vehicles and trains). 
(a)

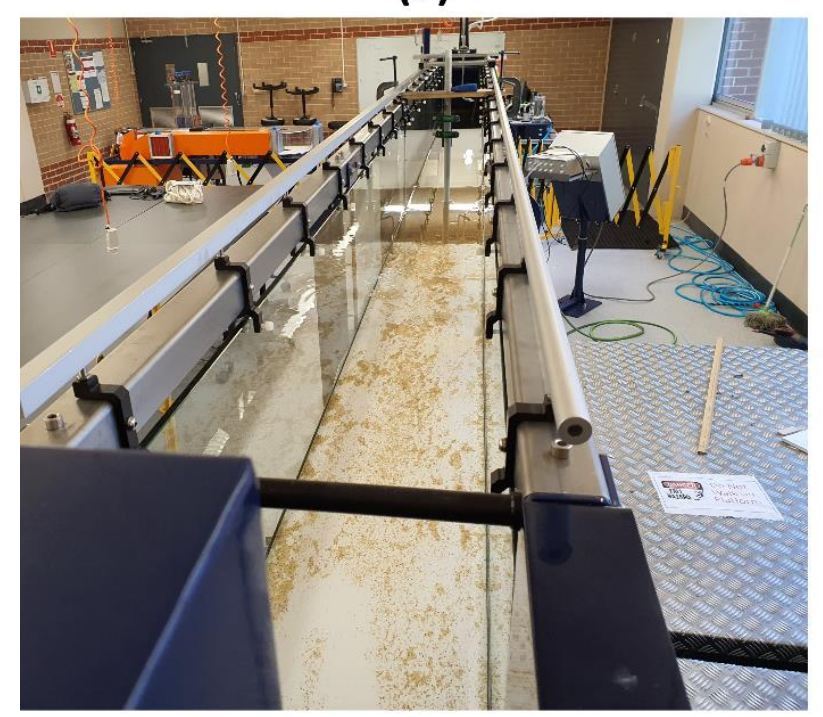

(c)

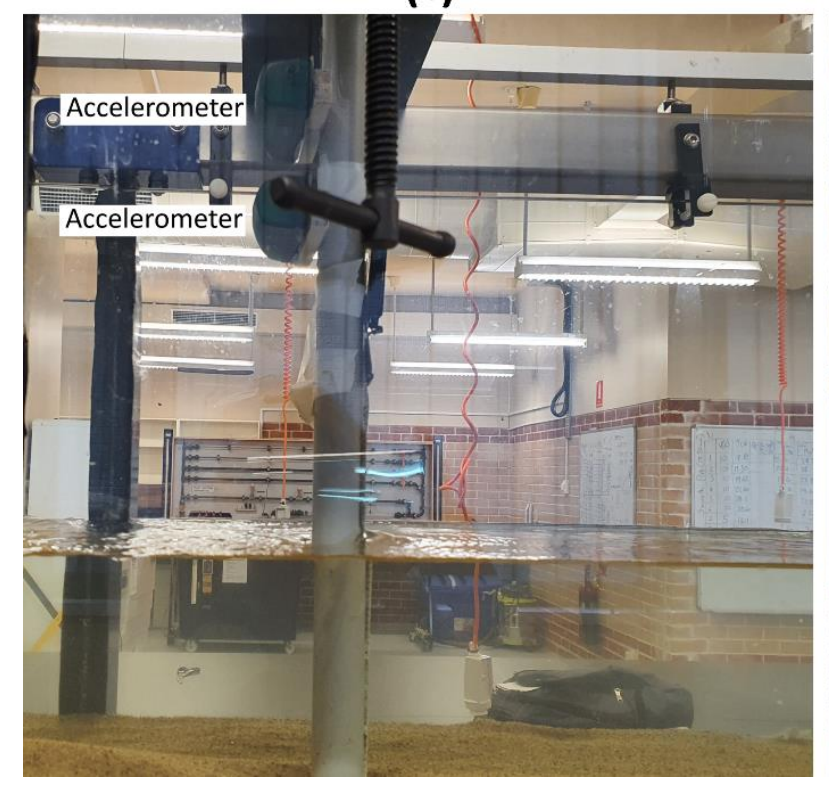

(b)

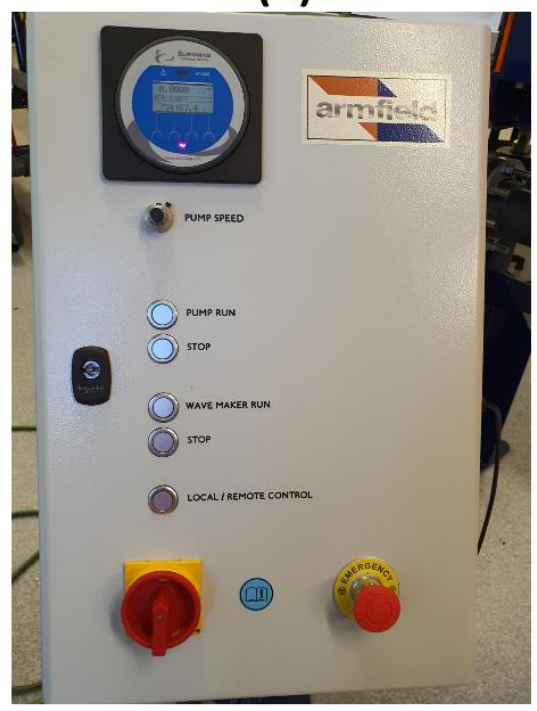

(d)

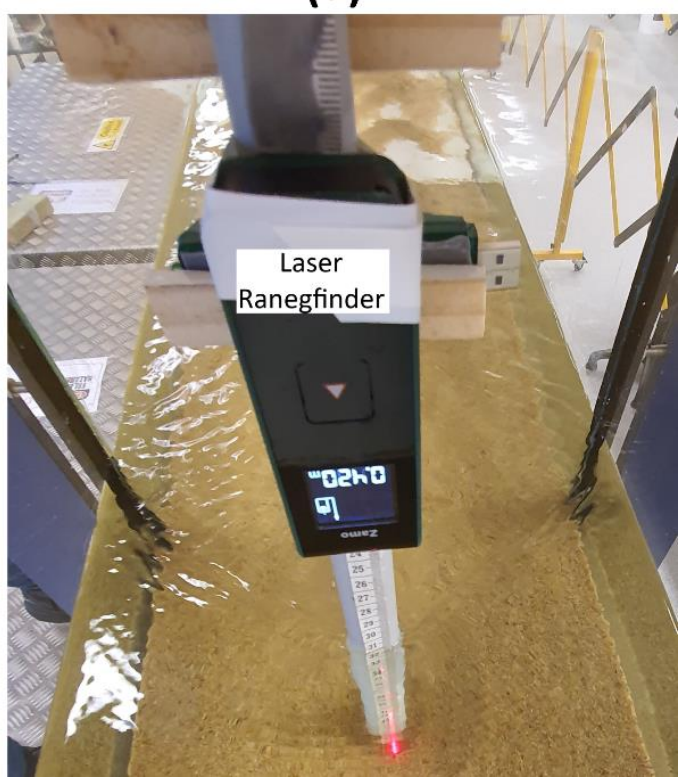

Figure 3. the hydraulic flume and model pier, and utilised instruments: (a) the photograph of the hydraulic flume, (b) the control panel of the pump, (c) two accelerometers mounted on the pier, and (d) the laser rangefinder mounted on the upstream side of the pier.

\subsection{Scaling Laws for Physical Modelling}

In the current physical modelling technique, Froude number similitude is chosen because the local scour near the bridge pier usually occurs in open channel flow. Since the flume provides an open channel, the flow is governed by the balancebetween inertial and gravitational forces and the ratio of these forces is called the Froude Number as shown in Equation 5 [47]:

$$
F r=\frac{V}{\sqrt{g \cdot h_{w}}}
$$

where, $V$ is the water velocity, $h_{w}$ is the water depth, and $g$ is the gravitational acceleration. Studies have shown that the effect of Reynold's number similitude can be negligible in scouring applications owing to its relatively high value, i.e. turbulent flow [5,47]. With Froude number similitude, the following scaling relationship can be w ritten 


$$
\begin{aligned}
& V_{r}=\sqrt{L_{r}} \\
& t_{r}=\sqrt{L_{r}}
\end{aligned}
$$

where $L_{r}$ is the scaling ratio of length in the model to length in prototype, Note that, hereafter, the subscript $r$ represents the scaling ratio. While, the Froude number similitude can be somewhat simplistic, considering more complex scaling law is beyond the scope of this paper. Among the shortcomings of such scaling approach, the sediment particle size distortion in the scaled model can be an important issue [e.g. 48, 49], following Melville and Chiew [50] and Melville and Coleman [5], we can conclude that the effect of the sediment particle size can be considered negligible under the experimental conditions in this study where $D / d_{p}>25$. As such, it is assumed that using the river sediments of the prototype in the scaled model does not cause any significant error in our study. Discussions on the effect of sediment size scaling in flume physical models can be found in a number of studies [e.g. 19], but it is beyond the scope of this paper.

The stiffness $(K)$ and the first natural frequency $(P N F)$ of a pier can be simplified using a cantilever beam approach as follows

$$
\begin{gathered}
K=\frac{48 E \cdot I}{h_{p}^{3}} \\
P N F=\frac{1}{2 \pi} \sqrt{\frac{K}{M}}
\end{gathered}
$$

where $E$ is the elastic modulus, $I=\pi / 64 \times\left(D_{\text {out }}^{4}-D_{\text {inn }}^{4}\right)$ is the second moment of area that can be found using the inner and outer diameter $\left(D_{\text {inn }}\right.$ and $D_{\text {out }}$ are the inner and outer diameter of the PVC pipe, respectively) for the model pier, $h_{p}$ is the height of unburied pier between the deck and the soil surface, and $M$ is the mass of the pier. Using these equations and knowing that $M=$ volume $\times$ density, we can arrive at the following scale relationships.

$$
\begin{gathered}
K_{r}=E_{r} \cdot I_{r} \cdot L_{r}^{-3} \\
(P N F)_{r}=K_{r}^{1 / 2} \cdot M_{r}^{-1 / 2} \\
I_{r}=L_{r}^{4} /\left[1-\left(D_{\text {inn }}^{4} / D_{\text {out }}^{4}\right)\right]
\end{gathered}
$$

where $\gamma$ is the density of the pier. The scaling factors derived based on Froude number similitude are provided in Table 1 along with the magnitude of parameters at both model and prototy pe scales. 
Table 1. Scaling laws and sca ling factors with corresponding magnitudes in model and prototype.

\begin{tabular}{|c|c|c|c|c|c|}
\hline \multirow{2}{*}{ Parameter } & \multirow{2}{*}{$\begin{array}{l}\text { Scaling factor } \\
\text { relationship }\end{array}$} & \multirow{2}{*}{ Scaling } & \multicolumn{2}{|c|}{ Magnitude } & \multirow{2}{*}{ Unit } \\
\hline & & & Model & Prototype & \\
\hline Length $\left(L_{r}\right)$ & $L_{r}$ & $1: 50$ & 0.3 & 15 & $m$ \\
\hline Pier width $(D)$ & $D_{r}=L_{r}$ & $1: 50$ & 0.025 & 1.25 & $m$ \\
\hline Scour depth $\left(d_{s}\right)$ & $d_{s, r}=L_{r}$ & $1: 50$ & $0.01^{*}$ & 0.5 & $m$ \\
\hline Sediment diameter $\left(d_{p}\right)$ & $d_{p, r}=1$ & $1: 1$ & 0.78 & 0.78 & $\mathrm{~mm}$ \\
\hline $\begin{array}{l}\text { Effective sediment } \\
\text { density }(\Delta \rho)\end{array}$ & $\Delta \rho_{r}=1$ & $1: 1$ & 1.6 & 1.60 & $\begin{array}{l}g \\
/ \mathrm{cm}^{3}\end{array}$ \\
\hline Water velocity $(V)$ & $V_{r}=L_{r}^{1 / 2}$ & $1: 7.071$ & 0.33 & 0.88 & $m / s$ \\
\hline Time $(T)$ & $T_{r}=L_{r}^{1 / 2}$ & $1: 50$ & $6^{*}$ & 300 & $h r$ \\
\hline Pier elastic modulus $(E)$ & $E_{r}$ & $1: 12$ & 2.5 & 30 & $M P a$ \\
\hline Pier density $(\gamma)$ & $\gamma_{r}$ & $1: 4.92$ & $0.406^{\wedge}$ & 2 & $\begin{array}{l}g \\
/ \mathrm{cm}^{3}\end{array}$ \\
\hline Mass of pier $(M)$ & $M_{r}=\gamma_{r} \cdot L_{r}^{3}$ & $1: 615,351$ & 0.0598 & 5206.5 & $k g$ \\
\hline $\begin{array}{l}\text { Second moment of area } \\
(I)\end{array}$ & $\begin{array}{l}I_{r} \\
=L_{r}^{4} \\
\cdot\left[1-\left(D_{\text {inn }}^{4} / D_{\text {out }}^{4}\right)\right]^{-1}\end{array}$ & $1: 12,447,010$ & $9.6 \mathrm{E}-9$ & $1.2 \mathrm{E}-1$ & $m^{4}$ \\
\hline $\begin{array}{c}\text { Stiffness of bridge pier } \\
\qquad(K)\end{array}$ & $K_{r}=E_{r} \cdot I_{r} \cdot L_{r}^{-3}$ & $1: 1,195$ & 43 & 18.1E6 & $N / m$ \\
\hline $\begin{array}{l}\text { First natural frequency } \\
\qquad(P N F)\end{array}$ & $\begin{array}{c}P N F_{r}=E_{r}^{1 / 2} \cdot \gamma_{r}^{-1 / 2} \cdot L_{r}^{-3} \\
\cdot I_{r}^{1 / 2}\end{array}$ & $22.7: 1$ & $42.01 \dagger$ & 92.56 & $H z$ \\
\hline & $\begin{array}{l}* \text { A typical test duration } \\
\wedge \text { The density calculated for } \\
\text { † PNF calculated for perfe }\end{array}$ & $\begin{array}{l}\text { time is used. } \\
\text { e hollow cylind } \\
\text { cantilever beam }\end{array}$ & & & \\
\hline
\end{tabular}

\subsection{Background on FDD and Data Analysis Procedure}

The data gathered during experiments are raw acceleration records and need to be adequately processed in order to estimate the modal parameters which can then be related to the measurement of scour depth. The technique employed in this paper is an extension of the classical frequency domain approach often referred to as the basic frequency domain (BFD) technique, or the peak picking technique. The classical approach is based on simple signal processing using a discrete FFT, and uses the fact that w ell separated modes can be estimated directly from the pow er spectral density matrix at the peak [51]. The classical techniques, how ever, can have difficulty detecting the close modes, and, the frequency estimates are limited by the frequency resolution of the spectral density estimate and, in all cases, damping estimation is uncertain or impossible [38].

The so-called Frequency Domain Decomposition (FDD) technique removes all the disadvantages associated with the classical approach, taking advantage of the Singular Value Decomposition (SVD) of the spectral matrix, the spectral matrix is decomposed into a set of auto spectral density functions, each corresponding to a single degree of freedom (SDOF) system. This result is exact in the case where the loading is white noise, the structure is lightly damped and when the mode shapes of close modes are geometrically orthogonal. If these assumptions are not satisfied the decomposition into SDOF systems is approximate, but still the results are significantly more accurate than the results of the classical approach [38].

The FDD method is based on the SVD of the measured PSD matrix of the recorded response, $\operatorname{Gyy}\left(f_{i}\right)$, at discrete frequencies of $f=f_{1}, f_{2}, \ldots, f_{i}$, as shown in Equation 5 , where $U(f)$ is a matrix of singular vectors and $S(f)$ is a diagonal matrix of singular values. Over the frequency range associated with each peak in the first singular values, the structural response is dominated by a single vibration mode, with the first singular vector being an estimate of the mode shape and the corresponding first singular value being the auto-PSD of the modal contribution [52].

$$
G_{y y}(f)=U(f)[S(f)] U^{T}(f)
$$

The data analysis using the FDD technique explained above, w as carried out in MATLAB2019. First, the recorded acceleration data from both accelerometers $w$ as imported into MATLAB and then 
a pre-processing procedure was used following the principles of Enhanced Frequency Domain Decomposition (EFDD) method [e.g. 53, 54] to filter the acceleration data. The first step in preprocessing is normalisation of all measurement channels (two channels in our experiments) to have zero mean and unit variance. Then, a narrow bandpass filter is applied to data. Following that, based on Welch's method, the PSD and SVD are calculated. In order to remove the harmonic components from the SVD curve, the Kurtosis test was conducted as described in details in the relevant literature $[53,55,56]$. Upon identifying and removing the harmonic components, peaks of SVD are picked, where the frequencies associated with the selected peaks are the natural frequency of the modes (PNFs). This procedure is repeated at 5-minute intervals of the collected acceleration data to enable the assessment of the change in PNFs versus time. It is worth noting that due to the low natural frequencies present in structural health monitoring applications, relatively long periods of data is required to ensure sufficient data points and peaks in the modal analysis, but EFDD provides an advantage over other methods of operational modal analysis (e.g. SSI-COV)

\section{Results and Discussion}

three experiments were conducted with different burial depths $\left(d_{b}\right)$ of $75 \mathrm{~mm}, 65 \mathrm{~mm}$, and $60 \mathrm{~mm}$, while all other experimental parameters were the same (see Table 2). The measured maximum scour depth versus time is presented in Figure $4 \mathrm{a}$ for these tests. It can be seen that the evolution of maximum scour depth is very similar between the threetests, although it may seem that scour development occurs faster test A with a smaller buried depth. This may be due to the slight differences (smaller than the tolerance of the measurements) betw een experimental parameters such as water velocity, or may be due to difference in the level of sand compaction, or even due to natural variability in soil characteristics. The cylinder is founded on free standinglocation and it has not any pile foundation connected to this pier and soil. Meanwhile, the soil near the bridge pier is compacted and soil bed is completely levelled. The general trends in evolution of maximum scour depth are very similar to those found in existing literature [e.g. 19]. An attempt w as made to characterise the scour development phases in Figure $4 \mathrm{~b}$ which present the normalised scour depth versus time with different phases as presented by Hoffmans and Verheij [57].

Table 2. experimental cha racteristics for the two tests.

\begin{tabular}{ccccc}
\hline Parameter & Test A & Test B & Test C & Unit \\
\hline Mean water velocity $(V)$ & 0.33 & 0.33 & 0.33 & $\mathrm{~m} / \mathrm{s}$ \\
\hdashline Pier diameter $(D)$ & 25 & 25 & 25 & $\mathrm{~mm}$ \\
Water height $\left(h_{w}\right)$ & 100 & 100 & 100 & $\mathrm{~mm}$ \\
\hdashline mean particle diameter $\left(d_{50}\right)$ & 0.78 & 0.78 & 0.78 & $\mathrm{~mm}$ \\
\hdashline Buried depth $\left(d_{b}\right)$ & 75 & 65 & 60 & $\mathrm{~mm}$ \\
\hline
\end{tabular}


(a)
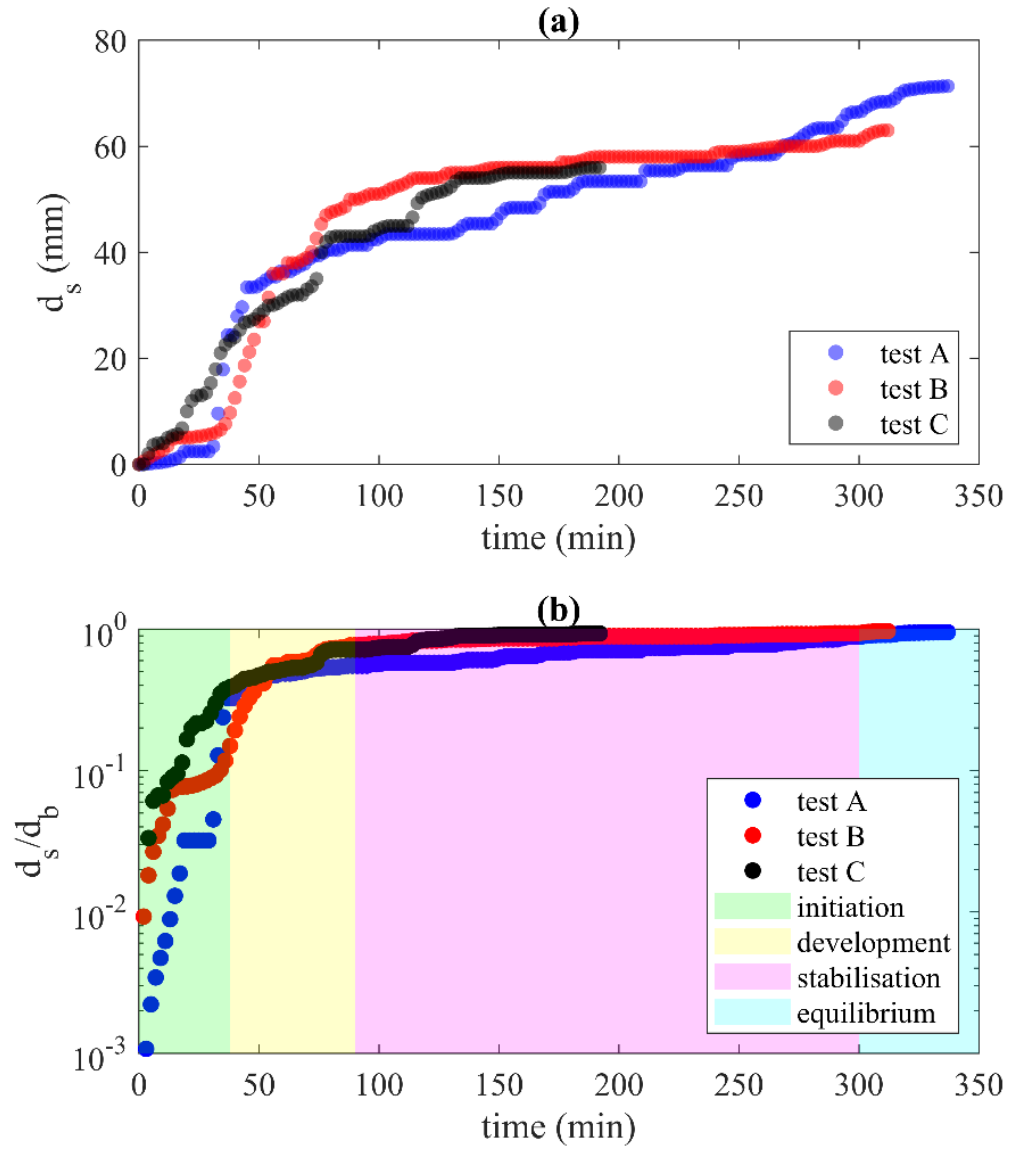

Figure 4. (a) evolution of maximum scour depth with time in both experiments; (b) normalised maximum scour de pth versus time with regards to diffe rent temporal phases of scour.

In order to show the extent of scouring zone around the pier, the photographs of the zone around the pier before and after scouring is depicted in Figure 5. It can be seen that prior to testing (Figure $5 a)$, the sand bed has a flat morphology as care was taken when preparing the soil to ensure surface has no wrinkle or ups and downs. After scouring (Figure 5b), scour hole is formed at upstream side of the pier which has a dimeter nearly 3 times of the pier diameter. On downstream, the sand particles have been deposited, consistent with observation of previous studies as presented in introduction and Figure 1c. 
(a)

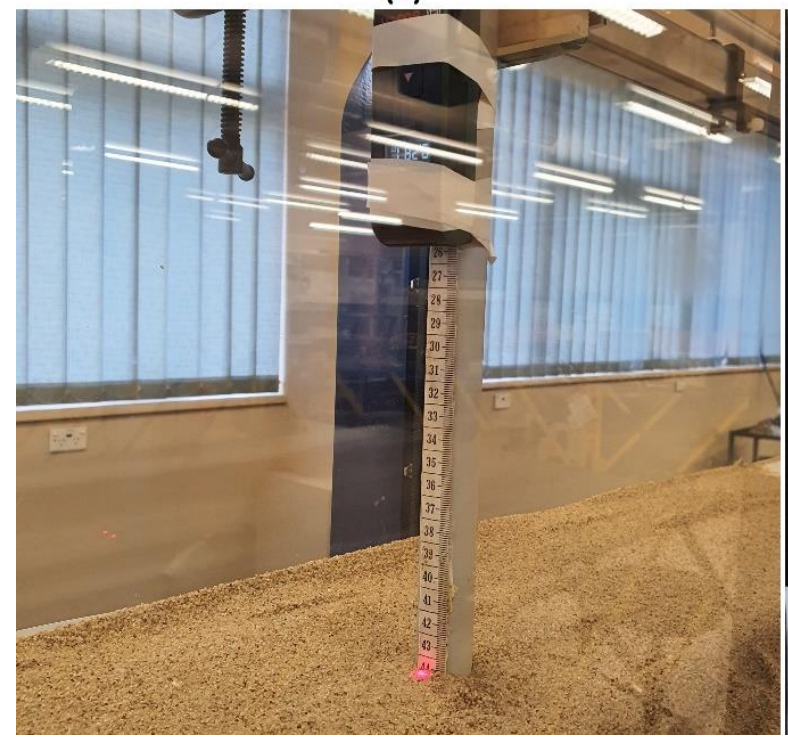

(b)

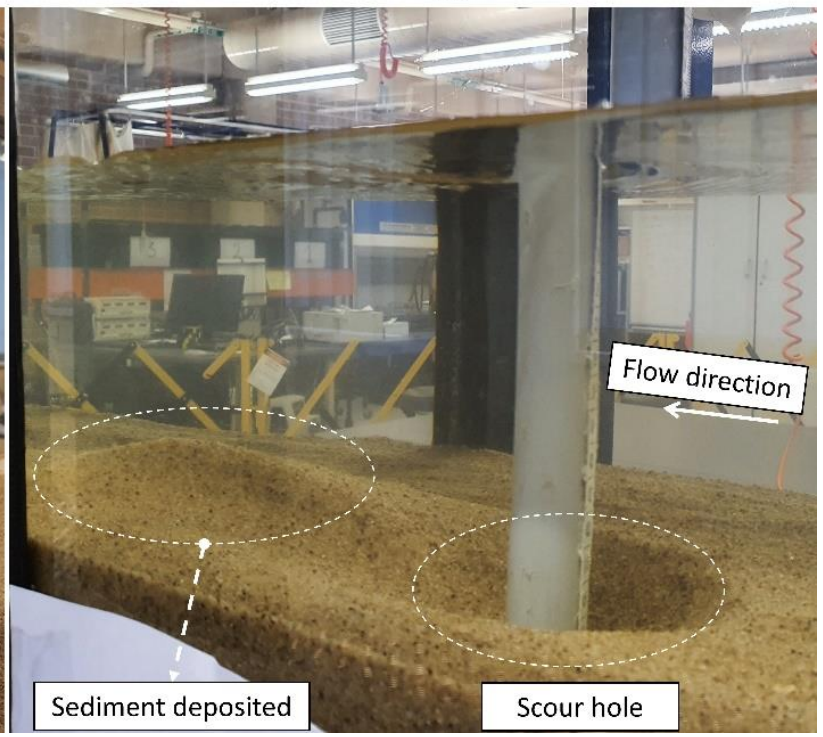

Figure 5. photographs of bridge pier and bed materials: (a) before water flow, (b) after 70 minutes of water flow.

The results of the modal analy sis and extracted PNFs in each experiment is also shown in Figure 6 for the first three modes. The right y-axis in these charts also show s the measured maximum scour depth. As explained earlier, the modal analysis using the EFDD techniques was conducted in 5 minute intervals through which the PNFs for the first three modes were extracted which captures the changes in PNFs of the deck-pier-bed structural system as a result of scour hole development. As it can be seen, all three modes in all three experiments show a steep reduction with time following the growth of the scour hole (i.e. increasing maximum scour depth). It also interestingly shows that during the initiation phase of scour hole evolution, the PNFs remain relatively unchanged but it decreases sharply within the development phase of scour hole evolution. As discus sed earlier, the reduction in natural frequency is due to change in the stiffness of the structural system which is compromised as a result of scour hole development around the pier. When the maximum scour hole reaches around 50 percent of the buried depth, the PNFs remains nearly constant, which suggests that relationship between the maximum scour depth and PNF is highly nonlinear. How ever, it should be noted that this latter effect may be due to the constrained boundary condition of the pier and the deck which are fixed to the sides of the hydraulic flume to simulate the effect of bridge abutment. As such, the experiments conducted in this study represent an ideal single pier bridge whose abutments have not affected by scouring, but in reality, the riverbed around the abutment may also undergo scouring which may further compromise the stiffness and hence its stability and the PNFs may continue to decrease beyond the 50 percent observed in these experiments. While the results of this study are generally in agreement with the existing literature that show a reducing trend in PNFs with the increasing maximum scour depth [e.g. 32], the existing literaturelacked a very clear trend of the temporal changes in PNFs mainly due to their limitations with their PNF ext raction techniques. 
(a)

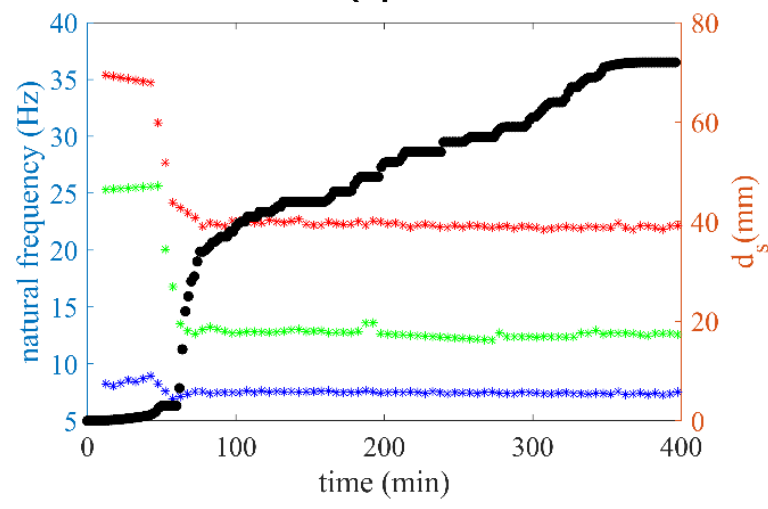

(c)

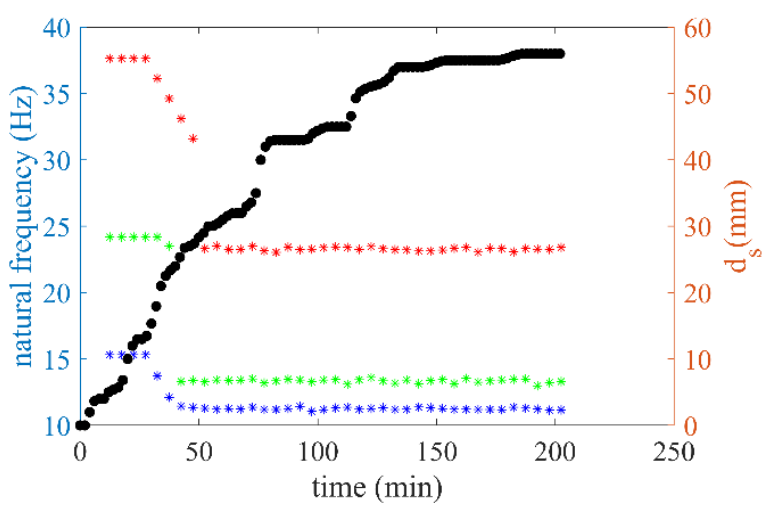

(b)

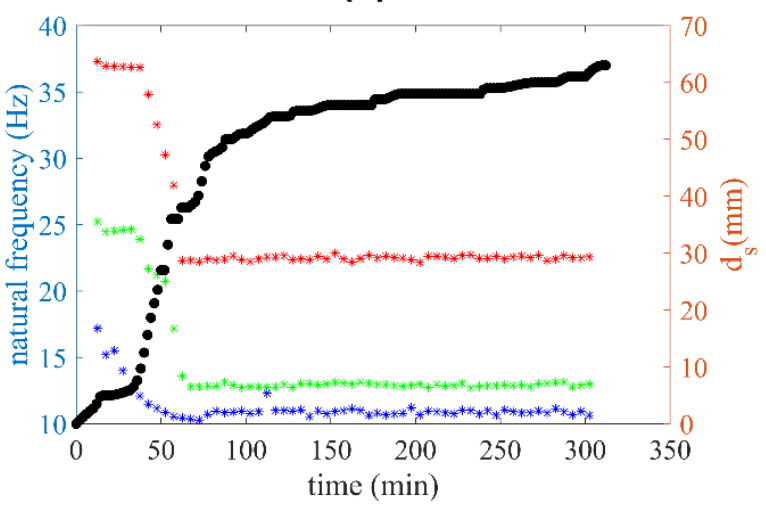

Figure 6. the temporal changes in the first three natural fre quency: (a) te st A, (b) test B, and (c) te st

C.

In order to further analyse the relationship between PNFs and the maximum scour depth, the dimensionless reduction of PNFs $\left(\delta \mathrm{f}_{\mathrm{n}}^{*}\right)$ were also presented versus the dimensionless maximum scour depth (the ratio of maximum scour depth to buried depth of the pier, $d_{s} / d_{b}$ ) in Figure 7 . Note that the reduction of PNFs is defined as $\delta f_{n}^{*}=\left(f_{n}^{0}-f_{n}\right) / f_{n}^{0}$, where $f_{n}^{0}$ is the initial unchanged PNF and $f_{n}$ is the instantaneous PNF. It can be seen that the second mode of frequency has the largest ultimate reduction in all three experiments, while the third modal frequency has the smallest. Figure 8 show $\mathrm{s}$ the average of the change in the first three modes of PNFs for each experiment. This chart can be considered as an attempt to relate the changes in PNFs to maximum scour depth and consequently the stability of a model bridge affected by scouring. Such approach for field application can provide a near real-time monitoring strategy (only 5-minute lag) for firsthand estimation of the scour hole depth around the pier. How ever, it should be noted that the variability and uncertainties is somewhat more pronounced here in Figure 7 and Figure 8, but the general conclusions drawn from Figure 6 is still valid. This chart can provide a practical guide for estimation and severity of the scour hole development. Further experimental, analytical and/or numerical works are required along $w$ it $h$ more advanced data analysis techniques to evaluate the impact of scour on the overall stability of the bridge, so that an early-warning threshold can be determined for different types of bridge based on the scour hole growth, but it is evident that for such ideal model bridge, a $\delta \mathrm{f}_{\mathrm{n}}^{*}$ value of 0.3 can be selected as an early warning threshold that coincides with $d_{s} / d_{b}$ value of 0.4-0.5. 
(a)

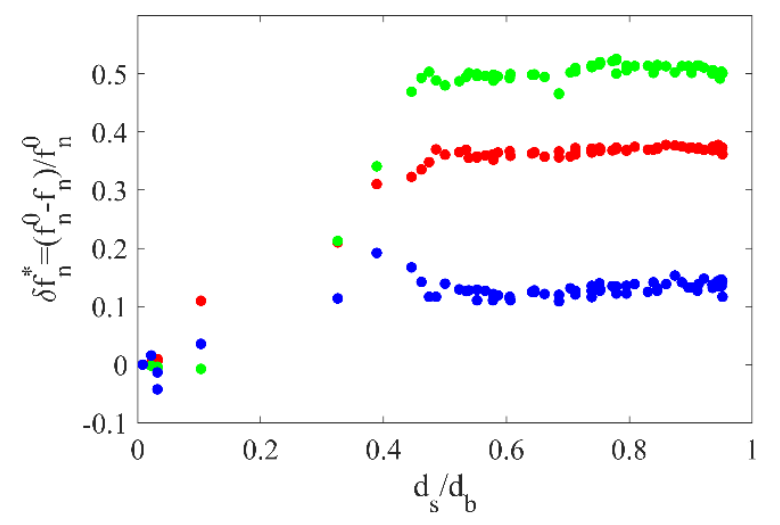

(c)

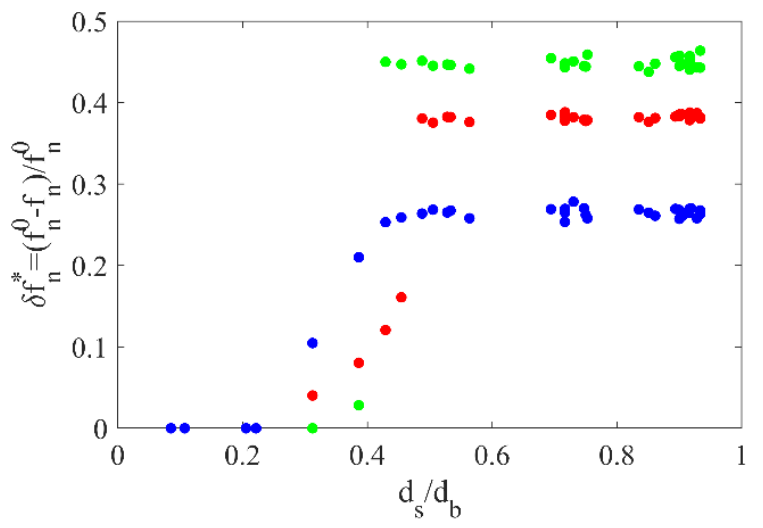

(b)

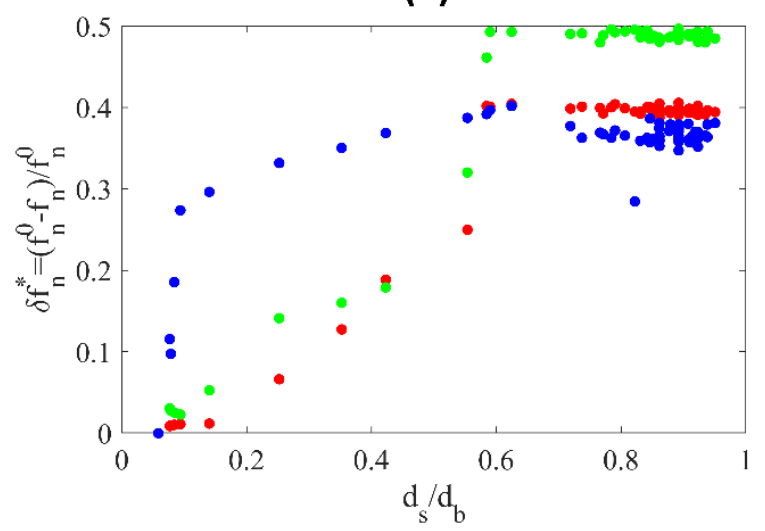

Figure 7. the dimensionless reduction in the first three natural frequency versus dimensionless maximum scour depth: (a) test $\mathrm{A}$, (b) test B and (c) test $\mathrm{C}$.

Another important observation from these figures is that the maximum scour depth increases so fast that the measured PNFs at the 5-minuteintervals seems insufficient. How ever, PNF estimation at smaller time intervals may become unreliable if not impossibleby EFDD technique (or any other technique for that matter), mainly because the acceleration data may not be enough for efficient estimation of PSD and SVD. This problem will not be rectified with recording data at a higher frequency as it can introduce additional layers of white noise to the data and it may not increase the data density at the desired frequency range at all. Thus, it is imperative to conduct experiments at lower water velocities where scour hole development takes place at a slower pace, in order to better capture the trend of $\delta \mathrm{f}_{\mathrm{n}}^{*}$ with respect to scour depth. 


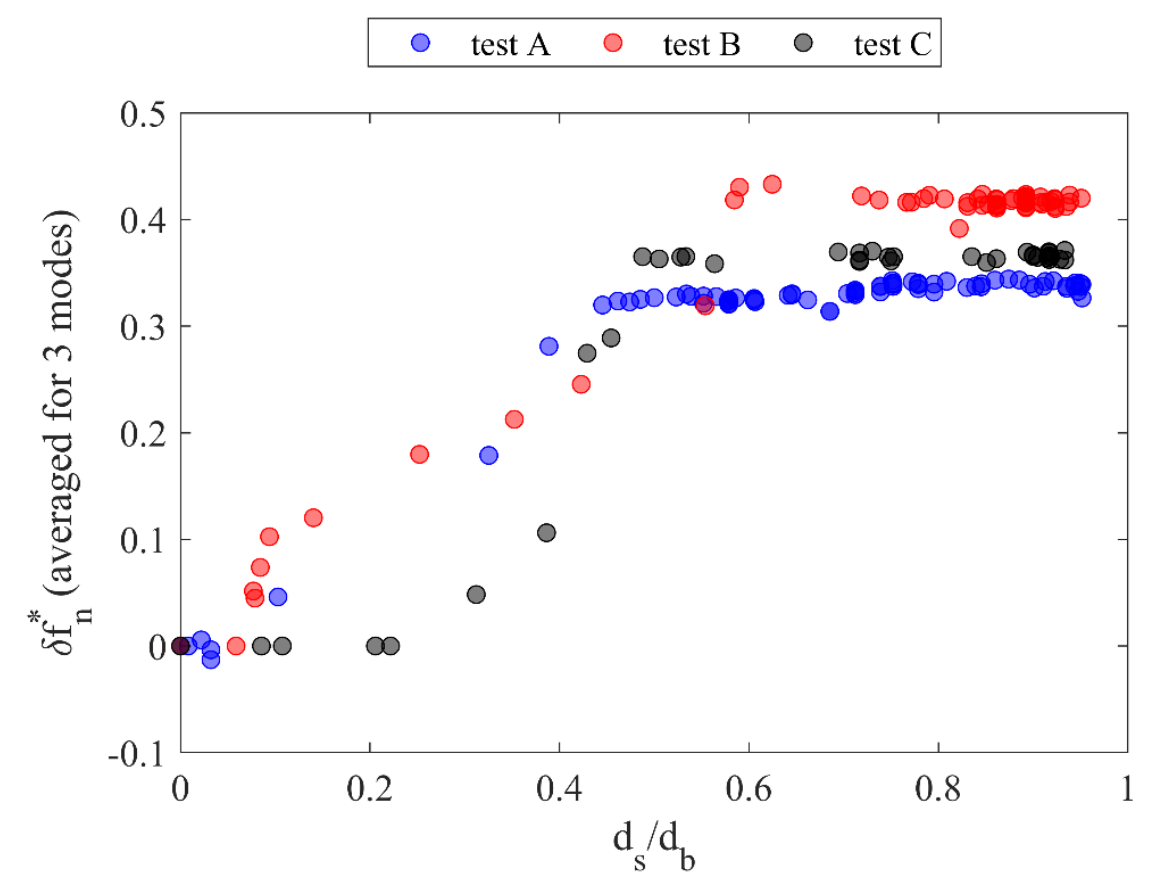

Figure 8. a veraged dimensionless reduction of the first three natural fre quency versus dimensionless maximum scour de pth: (a) test $A$, (b) test B and (c) test $C$.

\section{Conclusions and Future Developments}

This paper presents the results of a series of physical modelling studies on local scour around an ideal bridge pier, where an acceleration-based monitoring strategy has been utilised tow ards the development of a real-time monitoring technique. The acceleration-based monitoring techniques have been used in structural health monitoring for decades, but for bridge scour monitoring, it has been deemed challenging. This paper provides a novel framew ork which will serve as a building block for bridge stability monitoring. In this framew ork, a relatively new modal analysis technique (EFDD) has been employed that allows a more reliablePNF extraction form ambient vibration with short timelag (in order of few minutes). The promising results presented in this study is a giant leap tow ards the development of a low-cost real-time monitoring technique that can be applied to evaluate the stability of bridge.

It is of utmost importance to discuss the limitations of this study in the context of real-time monitoring of bridge stability. First and foremost, this study is a preliminary investigation of the relationship between the PNFs and maximum scour depth and does not consider some important aspects of bridge stability. Moreover, the bridge model in this study is a single pier bridge whose abutment have not been affected by scouring. Though, in reality the bridge abutment also undergoes scouring and may further reduce the stiffness of the bridge as a structure and consequently the estimated PNFs. Considering uncompromised bridge abutments is commonplace in experimental studies on scour hole evolution around pier in the literature, but when modelling the effect of scouring on bridge stability is important to also study the simultaneous effect of scour on abutment which can give a better picture of the stability of the bridge as a whole influenced by scouring. In addition, having multiple piers in a bridge and considering different arrangements for them can provide a more realistic model for bridge pier scour and the overall stability of the bridge. Moreover, advanced modal analyses are required to identify the mode shapes of the bridge pier under scour influence which will provide better indicators of bridge stability. While, we have only focused on extracted PNFs in this paper, the authors currently working on strategies to extract reliable mode shapes through EFDD technique, which will eventually provide a more comprehensive monitoring capabilities for bridge pier scour. It should be also noted that although the results presented in this paper provides promising results, the application of this algorithm in the real scale can be problematic to some extent. As an example, the scaled model here presented PNFs as high as $38 \mathrm{~Hz}$ 
but in the prototype scale it corresponds to a PNF of nearly $1.8 \mathrm{~Hz}$ and working with such small frequencies can potentially lead to large errors during harmonic removal and PNF extraction. Moreover, the nature of the deck-pier-bed system in a real bridge can potentially affect the monitoring process, where the interaction between these varying and inhomogeneous system can lead to some difficulties in scour development and PNF extraction.

From a hydraulics point of view, the development of scour hole can be affected by the water velocity. Therefore, a more rigorous study of the effect of water velocity on maximum scour depth and hence the extracted PNFs should be an immediate future study as it can reveal a better picture on the relationship between PNF and the scour depth. In this study, we have selected a velocity very close to the critical velocity but selecting low er velocities for future experiments allow s a more reliable and complete relationship between PNFs and maximum scour depth. It should also be noted that PNFs may not only be a function of maximum scour depth but also a function of the three dimensional shape of the scour hole, and therefore measurement of the three dimensional shape of the scour hole and its evolution with time at the same temporal resolution as the extracted PNFs can allow establishing a more rigorous relationship between the PNFs and scour hole development.

Another important aspect that has been largely neglected in studies of the scour hole development and its effect on bridge stability (including this study) is the role of soil types, their hydro-mechanical characteristics, and their variability. Given that scour hole develops as a result of water flow pattern around the soil surrounding the pier, it seems intuitive to heavily focus on hydromechanical properties of soil to better understand the local scour mechanisms and itsultimate impact on bridge stability. Most of existing experimental studies have used non-cohesive sandy soils, and while some studies attempted to study the role of cohesion of soil on pier scour [58], the role of other soil characteristics (e.g. consolidation, friction angle, cementation) is not fully understood yet. Therefore, it is important for future studies to focus on the effect of soil's natural variability on scour hole development and structural stability of the bridge.

\section{Appendix A. Peak Picking Through EFDD}

The acceleration data recorded by the accelerometers are first transformed from time domain into the frequency domain using the cross pow er spectral density. Then, the first singular value diagram is evaluated for peaks, for which the corresponding frequencies are the natural frequencies (PNFs). How ever, peak picking using the regular SVD diagram can be problematic as the harmonic components can present some peak that do not represent an actual mode of frequencies. In order to avoid this from happening, the harmonic components need to be removed from the SVD through the methodologies developed by Jacobsen, Andersen [53]. In this methodology, the following steps are taken in order:

- Each measurement channel is normalized to unit variance and zero mean

- For all frequencies between DC and the Nyquist frequency a narrow bandpass filtering of acceleration around the frequency is performed

- The Kurtosis for the filtered signal around the frequency is calculated

- For each frequency, the mean of the Kurtosis is calculated across the measurement channels

- The median of the Kurtosis of all frequencies is calculated. If the signal is purely Gaussian distributed this measure for the mean will theoretically be 0 .

- For each frequency, the deviation of the Kurtosis from the median is calculated. If Kurtosis deviates significantly from median of the Kurtosis, then the distribution around the frequency is different than for the majority of the other frequencies. In such a case the frequency can be characterised as an outlier that should not be included in the estimation of theSDOF functions

Figure A-1 depicts the first singular value diagram with and without the harmonic components and the green bands represents the frequency ranges with harmonic components detected. Then, the peak picking algorithm is performed on the SVD whose harmonic components hav e been removed as illustrated in Figure A-1. 


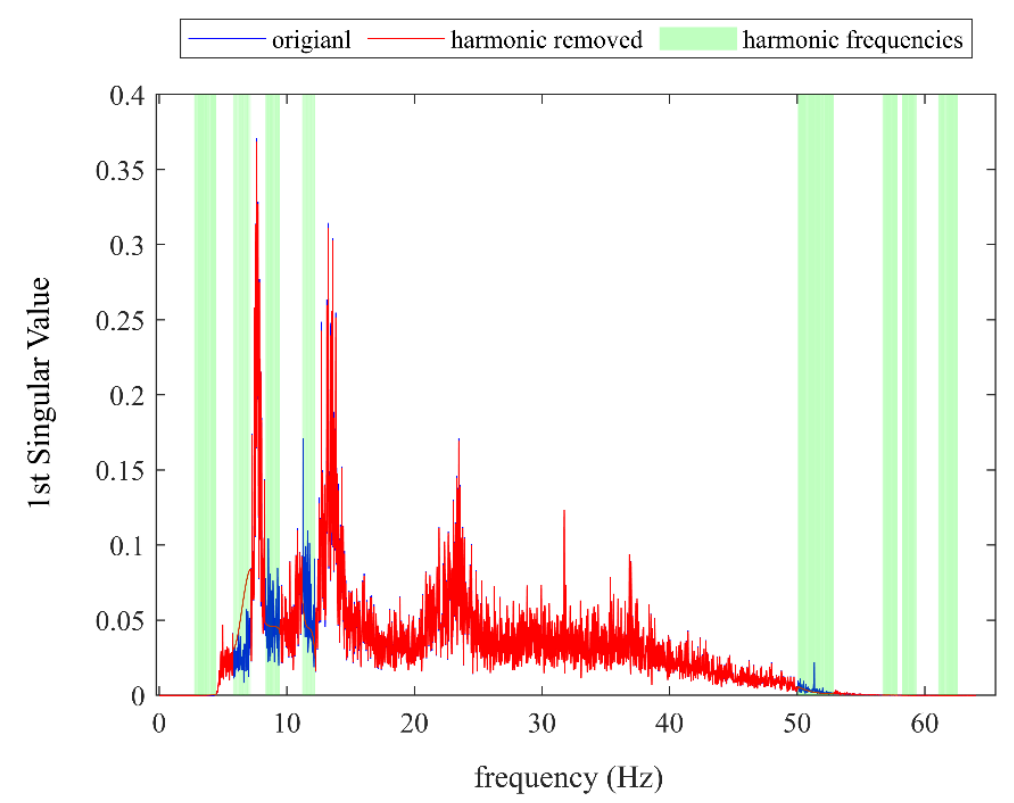

Figure A. removing the harmonic components of the SVD.

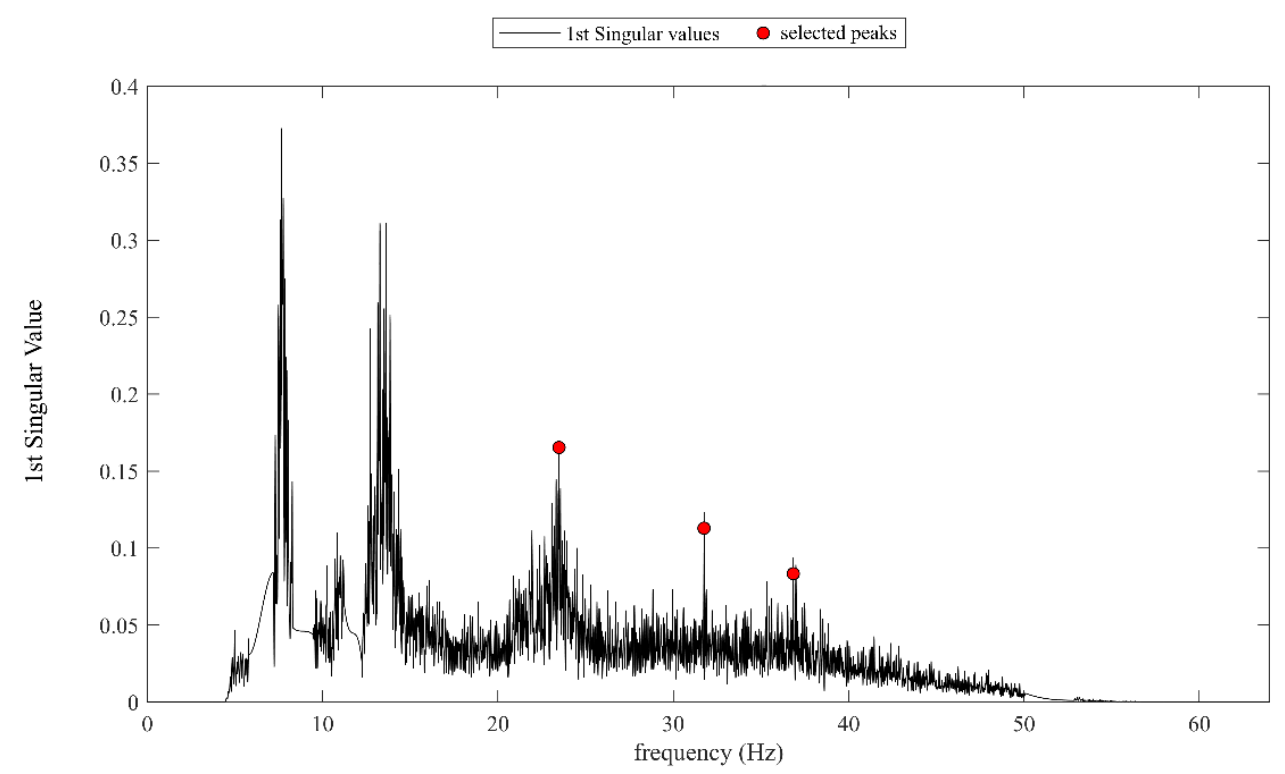

Figure A. a.

\section{References}

1. Lagasse, P.F., et al., Stream stability at highway structures. 2012, United States. Federal Highway Administration. Office of Bridge Technology.

2. Lagasse, P.F., P.L. Thompson, and S.A. Sabol, Guarding against scour. Civil Engineering, 1995. 65(6): p. 56.

3. Cook, W., P.J. Barr, and M.W. Halling, Bridge Failure Rate. Journal of Performance of Constructed Facilities, 2015. 29(3): p. 04014080.

4. Hamill, L., Bridge hydraulics. 1998: CRC Press.

5. Melville, B.W. and S.E. Coleman, Bridge scour. 2000: Water Resources Publication.

6. Briaud, J.-L., et al., SRICOS: Prediction of Scour Rate in Cohesive Soils at Bridge Piers. Journal of Geotechnical and Geoenvironmental Enginee ring, 1999. 125(4): p. 237-246.

7. Prendergast, L.J. and K. Gavin, A review of bridge scour monitoring techniques. Journal of Rock Mechanics and Geotechnical Enginee ring, 2014. 6(2): p. 138-149. 
8. Pizarro, A., S. Manfre da, and E. Tubaldi, The science behind scour at bridge foundations: a review. Wa ter, 2020. 12(2): p. 374.

9. Akan, A.O., Hydraulic Structures. Open ChannelHydraulics, 2006: p. 200-265.

10. Sumer, B.M., N. Christiansen, and J. Fredsøe, The horseshoe vortex and vortex shedding around a vertical wallmounted cylinder exposed to waves. Journal of Fluid Mechanics, 1997. 332: p. 41-70.

11. Bao, T. and Z. Liu, Vibration-based bridge scour detection: A review. Structural Control and He alth Monitoring, 2017. 24(7): p. e1937.

12. Jahangirzadeh, A., et al., Experimental and Numerical Investigationof the Effect of Different Shapes of Collars on the Reduction of Scour around a Single Bridge Pier. PLOS ONE, 2014. 9(6): p. e98592.

13. Hong, J.-H., et al., Predicting time-dependent pier scour depth with support vector regression. Journal of Hydrology, 2012. 468-469: p. 241-248.

14. Parola, A., et al., Effects of rectangular foundation geometry on local pier scour. Journal of Hydraulic Engineering, 1996. 122(1): p. 35-40.

15. Muzzammil, M. and T. Ganga dhariah, The mean characteristics ofhorseshoevortex at a cylindrical pier. Journal of Hydraulic Research, 2003. 41(3): p. 285-297.

16. Tafa rojnoruz, A., R. Gaudio, and S. Dey, Flow-altering countermeasures against scour at bridge piers: a review. Journal of Hydraulic Research, 2010. 48(4): p. 441-452.

17. Dey, S. and R.V. Raikar, Characteristics of Horseshoe Vortex in Developing Scour Holes at Piers. Journal of Hydraulic Engineering, 2007. 133(4): p. 399-413.

18. Guan, D., et al., Characterization of horseshoe vortex in a developing scour hole at a cylindrical bridge pier. International Journal of Se diment Research, 2019.34(2): p. 118-124.

19. Link, O., S. Henríquez, and B. Ettmer, Physical scale modelling of scour around bridge piers. Journal of Hydraulic Research, 2019. 57(2): p. 227-237.

20. Bauri, K.P. and A. Sarkar, Turbulent bursting events within equilibrium scour holes around aligned submerged cylinder. Journal of Turbulence, 2020. 21(2): p. 53-83.

21. Keshavarzi, A., B. Melville, and J. Ball, Three-dimensional analysis of coherent turbulent flow struct ure around a single circular bridge pier. Environmental Fluid Mechanics, 2014. 14(4): p. 821-847.

22. Keshavarzi, A., R. Gazni, and S.R. Homayoon, Prediction of scouring around an arch-shaped bed sill using Neuro-Fuzzy model. Applied Soft Computing, 2012. 12(1): p. 486-493.

23. Qaderi, K., et al., A comparative study of solo and hybrid data driven models forpredicting bridge pier scour depth. Marine Georesources \& Geotechnology, 2020: p. 1-11.

24. Williams, P., T. Bolisetti, and R. Balachandar, Evaluation of governing parameters on pier scour geometry. Canadian Journal of Civil Engineering, 2016. 44(1): p. 48-58.

25. Lam, E., et al. Prediction of pier scour depth at bridges with composite piers and headstock support ing struct ures. in 13th Hydraulics in Water Engineering Conference. 2017. Engineers Australia.

26. Pizarro, A., et al., Dimensionless Effective Flow Work for Estimation of Pier Scour Caused by Flood Waves. Journal of Hydraulic Engineering, 2017. 143(7): p. 06017006.

27. Alipour, A., B. Shafei, and M. Shinozuka, Evaluation of Uncertainties Associated with Designof Highway Bridges Considering the Effects of Scouring and Earthquake, in Structures Congress 2010. 2010. p. 288-297.

28. Jones, S.J. and E.V. Richardson. A Decade of High Priority Bridge Scour Research in the US. in Proceedings 2 nd International Conference on Scour and Erosion (ICSE-2). November 14.-17., 2004, Singapore. 2004.

29. Wang, C., X. Yu, and F. Liang, A review of bridge scour: mechanism, estimation, monitoring and countermeasures. Natural Hazards, 2017. 87(3): p. 1881-1906.

30. Foti, S. and D. Sabia, Influence of Foundation Scour on the Dynamic Response of an Existing Bridge. Journal of Bridge Engineering, 2011. 16(2): p. 295-304.

31. Prendergast, L.J., et al., An investigation of the changes in the nat ural frequency of a pile affected by scour. Journal of Sound and Vibration, 2013. 332(25): p. 6685-6702.

32. Yao, C., et al., Motion sensors for scourmonitoring: laboratory experiment with a shallowfoundation, in GeoFlorida 2010: Advances in Analysis, Modeling E Design. 2010. p. 970-979.

33. Briaud, J.-L., et al. Motion Sensors for Scour Monitoring: Laboratory Experiments and Numerical Simulations. The. in Transportation Research Board (TRB) 89th Annual Meeting . 2010.

34. Tserng, H.-P., et al., Application of Wireless Sensor Network to the Scour Monitoring System of Remote Bridges. International Journal Of Enginee ring And Technology, 2013.5(5): p. 641. 
35. Bao, T., Z.L. Liu, and K. Bird, Influence of soil characteristics on natural frequency-based bridge scour detection. Journal of Sound and Vibration, 2019. 446: p. 195-210.

36. Lin, T.-K. and Y.-S. Chang, Development of a real-time scour monitoring system for bridge safety evaluation. MechanicalSystems and Signal Processing, 2017. 82: p. 503-518.

37. Mao, Q., et al., Structural condition assessment of a bridge pier: A case study using experimental modal analysis and finite element model updating. Structural Control and Health Monitoring, 2019. 26(1): p. e2273.

38. Brincker, R., L. Zhang, and P. Andersen, Modal identification of output-only systems using frequency domain decomposition. Smartmaterials and structures, 2001. 10(3): p. 441.

39. Magalhães, F. and Á. Cunha, Explaining operational modal analysis with data froman arch bridge. Mechanical Systems and Signal Processing, 2011. 25(5): p. 1431-1450.

40. Torbol, M., Real-Time Frequency-Domain Decompositionfor Structural Health Monitoring Using General-Purpose Graphic Processing Unit. Computer-Aided Civil and Infrastructure Engineering, 2014. 29(9): p. 689-702.

41. Makki Alamdari, M., et al., Frequency domain decomposition-based multisensor data fusion for assessment of progressive damage in structures. Structural Control and Health Monitoring, 2019. 26(2): p. e2299.

42. Chen, Z., et al., Dynamic Behavior of Super High-Rise Building: Deployment of Smart Monitoring System and Analysis. Journal of Structural Engineering, 2020. 146(4): p. 05020001.

43. Malekjafarian, A. and E.J. Obrien, Identification of bridge mode shapes using Short Time Frequency Domain Decomposition of the responses measured in a passing vehicle. Enginee ring Structures, 2014. 81: p. 386-397.

44. Kong, X. and C.S. Cai, Scour effect on bridge and vehicle responses under bridge-vehicle-wave interaction. Journal of Bridge Enginee ring, 2016. 21(4): p. 04015083.

45. Prendergast, L.J., D. Hester, and K. Gavin, Determining the Presence of Scour around Bridge Foundations Using Vehicle-Induced Vibrations. Journal of Bridge Engineering, 2016. 21(10): p. 04016065.

46. Ranjbar-Zahedani, M., et al. Submerged flow diversion structure as an effective countermeasure to protect bridge piers from scour. in Australian Small Bridges Conference, 9th, 2019, Surfers Paradise, Queensland, Australia.2019.

47. Chanson, H., Hydraulics of Open Channel Flow: An Introduction. 2004: Else vier Butterworth-Heinemann.

48. Tabarestani, M.K. and S.A.J.M.J.o.C.E. Salamatian, Physical modelling of local scour around bridge pier. 2016. 28(3).

49. Melville, B.W. and A.J. Sutherland, Design Method for Local Scour at Bridge Piers. Journal of Hydraulic Engineering, 1988. 114(10): p. 1210-1226.

50. Melville, B.W. and Y.-M. Chiew, Time Scale for Local Scour at Bridge Piers. Journal of Hydraulic Enginee ring, 1999. 125(1): p. 59-65.

51. Bendat, J.S. and A.G. Piersol, Engineering applications of correlation and spectral analysis. $2^{\text {nd }}$ ed. New York. 1993, New York: Wiley.

52. KARIYAW ASAM, K., et al., Field Assessment of Ambient Vibration-Based Bridge Scour Detection. Structural Health Monitoring 2019, 2019.

53. Jacobsen, N.-J., P. Andersen, and R. Brincker. Using enhanced frequency domain decomposition as a robust technique to harmonic excitation in operational modal analysis. in Proceedings of ISMA2006: international conference on noise $\mathcal{E}$ vibrationengineering. 2006. Belgium Leuven.

54. Altunış1k, A.C., F.Y. Okur, and V. Kahya, Modal parameter identificationand vibrationbased damage detection of a multiple cracked cantileverbeam. Engineering Failure Analysis, 2017. 79: p. 154-170.

55. Andersen, P., et al. Estimating modal parameters of civil engineering structures subject to ambient and harmonic excitation. in Proceeding of EVACES 07 Conference. 2007.

56. Brincker, R.a.V., C.E. , Frequency-Domain Identification, in Introduction to Operational Modal Analysis. 2015, John Wiley \& Sons, Ltd: United Kingdom. p. 261-280.

57. Hoffmans, G.J.C.M. and H.J. Verheij, Scour Manual. 1997, Rotterdam, The Netherlands: Balkema.

58. Lodhi, A.S., et al., Influence of cohesion on scour at wake of partially submerged spur dikes in cohesive sediment mixtures. ISH Journal of Hydraulic Engineering, 2018: p. 1-12. 